\title{
Review on Corosolic Acid:Based on Various Pharmaceutical Effects
}

\section{Park Cheolin ${ }^{*}$, Lee Jae-Sik ${ }^{2}$}

\author{
${ }^{1}$ Department of Biomedical Laboratory Science, Daegu, Daegu Health College, South Korea \\ ${ }^{2}$ Department of Biomedical Laboratory Science, Hyejeon College, Hongseong, South Korea
}

\begin{abstract}
A B S T R A C T
Corosolic acid is a pentacyclic triterpene acid found in banaba leaves, Lagerstroemia speciosa which is similar in structure to useful pharmaceutical material such as ursolic acid and has been reported to have beneficial activities, as found in in vitro and several animal studies including human studies, particularly due to its effects on lowering of blood sugar. This review paper is focused on various pharmaceutical effects including decreasing of blood sugar of corosolic acid from published articels and can be helpful on the understanding of those effects which can be appliable on maintenace and treatment against several disease.
\end{abstract}

Keywords: corosolic acid, banaba, Lagerstroemia speciosa, pharmaceutical effects

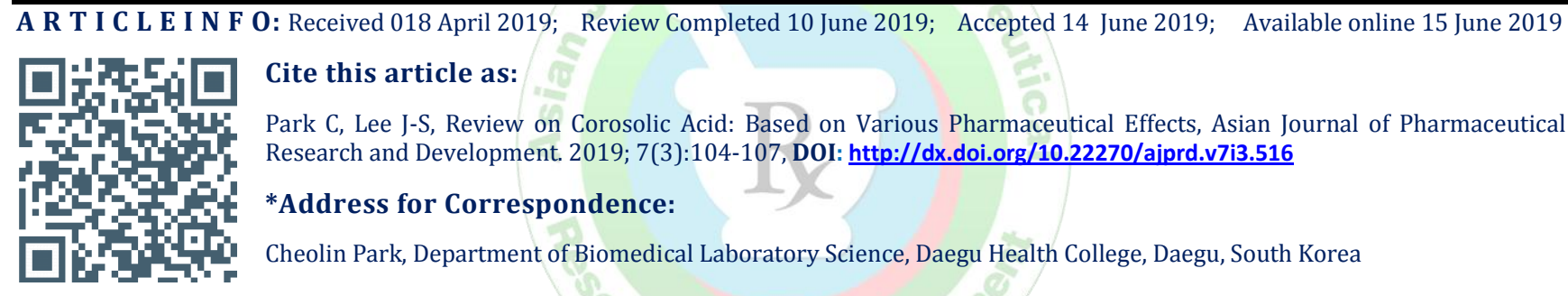

\section{INTRODUCTION}

$\mathrm{B}$ anaba is the best source of corosolic acid, a known agent that helps absorb glucose into blood cells according to several studies. Several of the active components (extracts) included in banaba leaf are corosolic acid and tannins, including lagerstroemia. There are two possible mechanisms of action for corosolic acid. The first is that it may improve the sensitivity of the insulin receptor on all cells of the body. Insulin has to bind to this receptor to allow blood glucose to enter the cells. If it does not bind to the receptor, this results in increased levels of insulin, which can damage the nerves, brain, eyes, and any other part of the body that is vulnerable to insulin damage. It is called insulin resistance which can be important factor to bring metabolic syndrome. Corosolic acid improves the sensitivity of the insulin receptor by inhibiting a protein in the body called tyrosine phosphates, which reduces insulin receptor site activity. The second path of action for corosolic acid involves its ability to open an entirely new path in cells for insulin to enter the cell. This is called the GLUT4 glucose transporter, which actions the taking-up of glucose into the muscles of the body which means a good effect on controlling of blood glucose levels. Besides these mechanisms, there are also studies that show corosolic acid can inhibit our own body's manufacture of glucose in a process called gluconeogenesis. This can have a important effect on lowering of blood glucose levels in the body.

\section{Effects of corosolic acid}

Corosolic acid (Figure 1) has been reported various biological properties including antidiabetic, antiinflammatory, antiproliferative, and protein kinase $\mathrm{C}$ inhibition activity ${ }^{1,2}$. It is found in numerous plants species, particularly Lagerstroemia speciosa called banaba as local name ${ }^{3}$.<smiles>CC(=O)C12CCC(C)C(C)C1C1CCC3C4(C)CC(=O)C(O)C(C)(C)C4CCC3(C)C1(C)CC2</smiles>

Figure 1: Structure of corosolic acid 


\section{Diabetes}

The most published articles about the function of corosolic acid is lowering blood sugar level in human and animal. It was first reported in 2006 that corosolic acid has a lowering effect on postprandial blood sugar levels in vivo from human studies ${ }^{4}$. Corosolic acid may improve the insulin resistance conditions. The work of insulin is controlled by tyrosine phosphorylation and initiated by the binding of insulin to the insulin receptor. Corosolic acid may act as an insulin sensitizer, enhancing insulin receptor B phosphorylation indirectly by inhibiting certain nonreceptor protein tyrosine phosphatases ${ }^{5}$. Corosolic acid may also stimulate GLUT4 glucose transporter course of glucose taking-up into muscle cells ${ }^{6}$. Another study reported that corosolic acid inhibited gluconeogenesis by increasing the production of the gluconeogenic intermediate fructose-2,6-bisphosphate in isolated hepatocytes, which can be corosolic acid may promote glycolysis ${ }^{7,8}$.Triterpene acids including corosolic acid isolated from Lagerstroemia speciosa leaves acts alphaglucosidase inhibitors ${ }^{9}$.

\section{Cancer}

Corosolic acid has toxic to cells' activity against several cancer cell lines of humans. The regulation may be associated with suppression of protein kinase C activity ${ }^{10}$. In addition, cytotoxic activity has been reported against HL-60 (leukemia carcinoma), MCF-7 (breast carcinoma), and Hep-G2 (hepatic carcinoma) from several human cell lines ${ }^{11}$.

Corosolic acid exerts their antineoplasticroles against colorectal cancer cells by encouraging the $\mathrm{N}$-terminal phosphorylation and subsequent proteasomal degradation of $\beta$-catenin ${ }^{12}$. Corosolic acid also isolated from the fruit of Crataegus pinnatifida presumed and mimiced a protein kinase $\mathrm{C}$ inhibitor as well as a cytotoxic agent ${ }^{10}$.

Corosolic acid was able to reverse the chemoresistance of epithelial ovarian cancer cells and suppress the cell-cell interaction with tumorigenic macrophages. It is suggested that corosolic acid may be useful as an adjuvant treatment to patients with advanced ovarian and other types of cancer due to the multiple anticancer effects ${ }^{13}$.

Corosolic acid impedes VEGFR2 kinase activity from hepatocellular carcinoma cell by direct interaction with the ATP binding pocket. Corosolic acid regulates the decrease of VEGFR2/Src/FAK/cdc42 axis, subsequently decreasing $\mathrm{F}$-actin formation and migratory activity in vitro $^{14}$.

\section{Inflammation}

The complement plays an pivotal role in immune defense against infection and inflammation. Activation of the complement system provides efficient means for protecting the host from the actions of invading antigens ${ }^{15}$. Several ursane-type tritermpenoids from including corosolic acid show anti-complementary activity ${ }^{16}$.Corosolic acid also blocks oxidative stress, inflammation and high blood pressure in SHR/NDmcr-cp rats $^{17}$.

\section{Obesity}

There is in vitro research result for corosolic acid hindering protein tyrosine phosphatase $1 \mathrm{~B}$; inhibition of this phosphatase is suggested as for an obesity treatment ${ }^{18}$. Corosolic acid presumes also a pancreatic lipase inhibitor, the essential enzyme for lipid consumption ${ }^{19}$. From an animal study, corosolic acid acted as a peroxisome proliferator-activated receptor alpha agonist, modulating lipid metabolism process and augmentating fatty acid beta-oxidation in the liver ${ }^{20}$.

\section{HIV}

Ellagic acid and gallic acid from Lagerstroemia speciosa inhibit HIV-1 infection through inhibition of HIV-1 protease $\&$ reverse transcriptase activity ${ }^{21}$. The purpose of this study was to appraise the anti-HIV characteristics of the extracts from the leaves of banaba, and further purification and characterization of the active components. The active elements for anti-HIV activity were gallic acid and ellagic acid, through inhibition of reverse transcriptase and HIV protease, respectively and so could be regarded as favorable candidates for the improvement of anti-HIV-1 materials ${ }^{21}$.

\section{Metabolic syndrome}

Metabolic syndrome means a condition in which several risk factors for cardiovascular disease and type II diabetes, abdominal obesity, hypertension, bad lipid metabolism and insulin resistance are occurred together.In an animal study for metabolic syndrome, corosolic acid had antihypertensive, lipid-lowering, antioxidant, and antiinflammatory effects on rats ${ }^{22}$. In a similar animal study, corosolic acid also reduced blood pressure and serum-free fatty acid levels ${ }^{23}$.

\section{Cholesterol}

In patients with type II diabetes mellitus intestinal cholesterol synthesis and cholesterol esterification is increased ${ }^{24}$. This is very important stuff because diabetes coupled with high blood cholesterol increases the risk of cardiovascular disease (CVD). Corosolic acid has been show to reduce cholesterol absorption process in the small intestine via inhibition of activity of cholesterol acyltransferase ${ }^{25}$.

\section{Side effects of corosolic acid}

Some side effects of corosolic acid include skin rashes, headaches and fatigue. According to research, these side effects will most likely be experienced by individuals who exceed the optimal dosage. It is not recommended for consumption by children or during pregnancy.

No adverse effects about corosolic acid or banaba did not reported in clinical trials. Contrary to the logical expectation that the blood sugar-lowering capacity of banaba would cause low blood sugar (hypoglycemia), 6 clinical human trials did not lead to any such effect ${ }^{4}$.

Another human study showed that Glucosol ${ }^{\mathrm{TM}}$ (soft capsule form of brand name containing $1 \%$ corosolic acid from banaba leaves, Lagerstroemia speciosa) had been applied and checked the blood sugar levels and side effects of 56 subjects. This group concluded that corosolic acid had a lowering blood sugar levels but no adverse effects such as rash, nausea and others ${ }^{26}$.

\section{CONCLUSION}

Corosolic acid (CRA), one of components of banaba leaves, has been reported to have anti-inflammatory and 
hypoglycemic actions, it can improve hypertension, abnormal lipid metabolism, and oxidative stress as well as the inflammatory state in SHR-cp rats, suggests CRA can be beneficial for preventing atherosclerosis-related diseases $^{18,22}$.

Most of research about corosolic acid focuses on the extracts or compound's efficacy in diabetes. There are two possible mechanisms of action for corosolic acid. The first is that it may improve the sensitivity of the insulin receptor on all cells of the body. Insulin has to bind to this receptor to allow blood glucose to enter the cells of body. If it does not bind to the receptor, this results in increased levels of insulin in blood, which can damage the nerves, brain, eyes, and any other part of the body that is vulnerable to insulin damage. Corosolic acid improves the sensitivity of the insulin receptor by inhibiting a protein in the body called tyrosine phosphatase, which reduces insulin receptor site activity ${ }^{18,30}$. The second path of action for corosolic acid involves its ability to open an entirely new path in cells for insulin to enter the cell. This pathway is called the GLUT4 glucose transporter, which facilitates the uptake of glucose into the muscles of the body. This has a huge effect on blood glucose levels because there is so much muscle mass in the body ${ }^{6}$.

However, varioius researches were reported about other effects from human and animal studies. Corosolic acid significantly prevents cell growth in both a dose- and a time-dependent way, influences apoptosis is related with the activation of caspases via a mitochondrial pathway, suggests it could have strong influence in advancing cancer chemotherapy for clinical utilization ${ }^{27}$.

Corosolic acid can suppress the M2 polarization of macrophages and tumor cell proliferation by inhibiting both STAT3 and NF- $\mathrm{BB}$ activation, thus, it might be a possible new way and treatment for tumor prevention and therapy $^{28}$.

\section{REFERENCES}

1. Wen X, Sun H, Liu J, Wu G, Zhang L, Wu X, Ni P. Pentacyclic triterpenes. Part 1: The first examples of naturally occurring pentacyclic triterpenes as a new class of inhibitors of glycogen phosphorylases. Bioorganic \& Medicinal Chemistry Letters. 2005; 15(22):4944-8.

2. Jung M, Park M, Lee HC, Kang YH, Kang ES, Kim SK. Antidiabetic agents from medicinal plants. Current Medicinal Chemistry. 2006; 13(10):1203-8.

3. Washino T, Kato Y, Zeida M, Minami H, inventors. Hypoglycemic banaba (Lagerstroemia speciosa ) extracts. US patent 2005-JP7255. April 14, 2004.

4. Egawa K, Takemoto J, Kajimoto Y, Yonaha N, Miura T, Kaneko T, Nishi Y, Mitsui R, Fujita Y, Yamada Y, Seino Y. Effect of corosolic acid on postchallenge plasma glucose levels. Diabetes Research and Clinical Practice. 2006; 73(2):174-7

5. Shi L, Zhang W, Zhou YY, Zhang YN, Li JY, Hu LH, Li J. Corosolic acid stimulates glucose uptake via enhancing insulin receptor phosphorylation. European Journal of Pharmacology. 2008; 584(1):21-9.

6. Miura T, Itoh Y, Kaneko T, Ueda N, Ishida T, Fukushima M, Matsuyama F, Seino Y. Corosolic acid induces GLUT4 translocation in genetically type 2 diabetic mice. Biological and Pharmaceutical Bulletin. 2004; 27(7):1103-5.

7. Yamada K, Hosokawa M, Fujimoto S, Fujiwara H, Fujita Y, Harada N, Yamada C, Fukushima M, Ueda N, Kaneko

ISSN: 2320-4850
Corosolic acid has antidiabetic effects (especially type 2 diabetes) which can improve glucose metabolism by decreasing insulin resistance; it prevents the enzymatic activities of several diabetes-related non-receptor protein tyrosine phosphatases (PTPs) in vitro ${ }^{29,30}$.

Corosolic acid has antitumor effects in sarcoma rat model through importantly impairing subcutaneous tumor development and lung metastasis and targeting the immunosuppressive activity of myeloid-derived suppressor cells (MDSC), and can aggrandize the antitumor effects of adriamycin and cisplatin in in vitro $^{31}$. Corosolic acid reduces 5-Fluorouracil (5-FU) chemo resistance, which is one of the most commonly used chemo therapeutic agents by activating AMPK from human gastric cancer cells ${ }^{32}$.

Corosolic acid which is isolated from Eriobotrya japonica (loquat) reveals anti-melanogenesis, anti-acne, anti-allergy and anti-aging activities ${ }^{33}$.

Corosolic acid as a pentacyclic triterpenes significantly inhibited osteosarcoma of MG-63 cells in a dose-and time-dependent manner and this provides that corosolic acid may be useful chemotherpeutic material for osteosarcoma ${ }^{34}$.

Corosolic acid exerts anti-inflammatory effects by regulating phosphorylation of interleukin receptorassoceated kinase (IRAK-2) via the NF- $\mathrm{KB}$ cascade in mouse BMDMs and may be useful as a pharmocological agent to prevent acute infammation ${ }^{35}$.

Besides these various effects, there are lots of studies about valuable effects on different human disease but it still has limitation to develop the powerful and effective phamacological effects. Consequently, corosolic acid isolated from banaba leaves and other herbs have future possible applications on clinical treatment as ingredients of drugs, functional foods for health benefits.

T, Matsuyama F, Yamada Y, Seino Y, Inagaki N.Effect of corosolic acid on gluconeogenesis in rat liver. Diabetes Research and Clinical Practice. 2008; 80(1):48-55.

8. Klein G, Kim J, Himmeldirk K, Cao Y, Chen X. Antidiabetes and anti-obesity activity of Lagerstroemia speciosa. Evidence-Based Complement and Alternative Medicine. 2007; 4(4):401-7.

9. Hou W, Li Y, Zhang Q, Wei X, Peng A, Chen L, Wei Y. Triterpene acids isolated from Lagerstroemia speciosa leaves as a-glucosidase inhibitors. Phytotherapy research. 2009; 23(5):614-8.

10. Ahn KS, Hahm MS, Park EJ, Lee HK, Kim IH. Corosolic acid isolated from the fruit of Crataegus pinnatifida var. psilosa is a protein kinase $\mathrm{C}$ inhibitor as well as a cytotoxic agent. Planta Medica. 1998; 64(5):468-70.

11. Akihisa T, Kama S, Uchiyama T. Cytotoxic activity of Perilla frutescens var. japonica leaf extract is due to high concentractions of oleanolic and ursolic acids. Journal of Natural Medicine. 2006;60(4):331-3.

12. Kim JH, Kim YH, Song GY, Kim DE, Jeong YJ, Liu KH, Chung YH, Oh S.Ursolic acid and its natural derivative corosolic acid suppress the proliferation of APC-mutated colon cancer cells through promotion of $\beta$-catenin degradation. Food and Chemical Toxicology.2014; 67:8795.

13. Fujiwara Y, Takaishi K, Nakao J, Ikeda T, Katabuchi H, Takeya M, Komohara Y.Corosolic acid enhances the antitumor effects of chemotherapy on epithelial ovarian cancer by inhibiting signal transducer and activator of 
transcription 3 signaling. Oncology Letters.2013; 161923.

14. Ku CY, Wang YR, Lin HY, Lu SC, Lin JY. Corosolic Acid Inhibits Hepatocellular Carcinoma Cell Migration by Targeting the VEGFR2/Src/FAK Pathway. PLOSone. 2015; DOI:10.1371/journal.pone.0126725.

15. Ember JA, Hugli TE. Complement factors and their receptors. Immunopharmacology. 1997; 38:3-15.

16. Thuong PT, Min BS, Jin W, Na M, Lee J, Seong R, Lee YM, Song K, Seong Y, Lee HK, Bae K, Kang SS. Anticomplementary activity of ursane-type triterpenoids from Weigela subsessilis. Biological \& Pharmaceutical Bulletin. 2006;29(4):830-3.

17. Yamaguchi Y, Yamada K, Yoshikawa N, Nakamura K, Haginaka J, Kunitomo M. Corosolic acid prevents oxidative stress, inflammation and hypertension in SHR/NDmcr-cp rats, a model of metabolic syndrome. Life Sciences. 2006;79(26):2474-9.

18. Na M, Yang S, He L, Oh H, Kim BS, Oh WK, Kim BY, Ahn JS.Inhibition of protein tyrosine phosphatase $1 \mathrm{~B}$ by ursane-type triterpenes isolated from Symplocos paniculata . Planta Medica. 2006; 72(3):261-3.

19. Jang DS, Lee GY, Kim J, Lee YM, Kim JM, Kim YS, Kim JS.A new pancreatic lipase inhibitor isolated from the roots of Actinidia arguta. Archives of Pharmacal Research. 2008; 31(5):666-70.

20. Yamada K, Hosokawa M, Yamada C, Watanabe R, Fujimoto S, Fujiwara H, Kunitomo M, Miura T, Kaneko T, Tsuda K, Seino Y, Inagaki N.Dietary corosolic acid ameliorates obesity and hepatic steatosis in KK-Ay mice. Biological and Pharmceutical Bulletin. 2008; 31(4):651-5.

21. Nutan, Modi M, Goel T, Das T, Malik S, Suri S, Rawat AK, Srivastava SK, Tuli R, Malhotra S, Gupta SK. Ellagic acid \& gallic acid from Lagerstroemia speciosa L. inhibit HIV-1 infection through inhibition of HIV-1 protease \& reverse transcriptase activity. The Indian Journal of Medical Research. 2013; 137(3):540-8.

22. Yamaguchi Y, Yamada K, Yoshikawa N, Nakamura K, Haginaka J, Kunitomo M. Corosolic acid prevents oxidative stress, inflammation and hypertension in SHR/NDmcr-cp rats, a model of metabolic syndrome. Life Sci . 2006; 79(26):2474-9.

23. Kunitomo M. Oxidative stress and atherosclerosis [in Japanese]. Yakugaku Zasshi . 2007; 127(12):1997-2014.

24. Aguirre MC, Delporte C, Backhouse N. Topical antiinflammatory activity of 2 alpha-hydroxy pentacyclic triterpene acids from the leaves of Ugni molinae. Bioorganic \& Medicinal Chemistry Letters. 2006; 14(16):5673-7.

25. Takayama H, Kitajima M, Ishizuka T, Seo S. Process for producing corosolic acid. US patent 2004-866733. June

\section{$15,2004$.}

26. William V. Judy A, Siva P. Hari B, Stogsdill A, Janet S. Judy A, Yousry MA, Naguib B, Richard P. Antidiabetic activity of a standardized extract (GlucosolTM) from Lagerstroemia speciosa leaves in Type II diabetics: A dose-dependence study. Journal of Ethnopharmacology. 2003; 87(1):115-7.

27. Xu Y, Ge R, Du J, Xin H, Yi T, Sheng J, Wang Y, Ling C. Corosolic acid induces apoptosis through mitochondrial pathway and caspases activation in human cervix adenocarcinoma HeLa cells. Cancer Letters. 2009; 2 84:229-37.

28. Fujiwara Y, Komohara Y, Ikeda T, Takeya M. Corosolic acid inhibits glioblastoma cell proliferation by suppressing the activation of signal transducer and activator of transcription-3 and nuclear factor-kappa B in tumor cells and tumor-associated macrophages. Cancer Science. 2011; 102:206-11.

29. Miura T, Ueda N, Yamada K, Fukushima M, Ishida T, Kaneko T, Matsuyama F, Seino Y.Antidiabetic effects of corosolic acid in KK-Ay diabetic mice. Biological and Pharmaceutical Bulletin. 2006; 29(3):585-7.

30. Shi L, Zhang W, Zhou YY, Zhang YN, Li JY, Hu LH, Li J. Corosolic acid stimulates glucose uptake via enhancing insulin receptor phosphorylation. European Journal of Pharmacology. 2008; 584(1):21-9.

31. Horlad H, Fujiwara Y, Takemura K, Ohnishi K, Ikeda T, Tsukamoto H, Mizuta H, Nishimura Y, Takeya M, Komohara Y.Corosolic acid impairs tumor development and lung metastasis by inhibiting the immunosuppressive activity of myeloid-derived suppressor cells. Molecular Nutrition and Food Research. 2013; 57:104654.

32. Park JB, Lee JS, Lee MS, Cha EY, Kim S, Sul JY. Corosolic acid reduces 5-FU chemoresistance in human gastric cancer cells by activating AMPK. Molecular Medicine Reports. 2018; 18(3):2880-8

33. Tan H, Sonam T, Shimizu K. The Potential of Triterpenoids from Loquat Leaves (Eriobotrya japonica) for Prevention and Treatment of Skin Disorder. International Journal of Molecular Sciences. 2017 May 11; 18(5). pii: E1030. doi: 10.3390/ijms 18051030.

34. Jia Y, Yuan H, Shan S, Xu G, Yu J, Zhao C, Mou X. Corosolic acid inhibits the proliferation of osteosarcoma cells by inducing apoptosis. Oncology Letters. 2016; 12(5):4187-94

35. Kim S, Cha JY, Kang HS, Lee JH, Lee JY, Park JH, Bae $\mathrm{JH}$, Song DK, Im SS. Corosolic acid ameliorates acute inflammation through inhibition of IRAK-1 phosphorylation in macrophages. BMB Reports. 2016; 49(5):276-81. 